\title{
REPERTORIUM VAN TIJDSCHRIFTLITERATUUR OP HET GEBIED VAN ACCOUNTANCY EN BEDRIJFSHUISHOUDKUNDE
}

Verschijnt maandelijks, behalve in augustus Samengesteld door de Stichting voor Economisch Onderzoek der Universiteit van Amsterdam, redactie: Mevr. Dra. E. Hijmans

\section{A. ACCOUNTANCY}

\section{HET ACCOUNTANTSBEROEP}

The Accountants' Function

"Infallibility" or "Skill and Judgment"?

Carrington, A. S. - Het publiek is dikwijls geneigd te menen dat accountants absoluut nauwkeurige gegevens verstrekken, en dat onzekerheden of waarschijnlijkheden geen plaats hebben in het beroep. Dergelijke meningen zijn niet alleen onjuist, maar ook ongewenst. Immers, de noodzaak van het weloverwogen oordeel is in feite de basis van het grootste gedeelte van de arbeid welke de accountant verricht; hij is geen ",rekenmachine". maar een man met een beroep dat hoge eisen stelt aan het oordeel en de kundigheid. De ..standing" van het beroep wordt dus in gevaar gebracht door de aangehaalde misvattingen. De schrijver gaat na, waardoor deze zijn ontstaan en geeft enkele suggesties voor bestrijding ervan.

In de eerste plaats is nodig dat elke accountant zich voortdurend bewust is en blijft van de grenzen die aan het in geldbedragen uitdrukken van het werkelijke gebeuren zijn gesteld en van de noodzaak om de methoden van de accountancy met oordeel en verstand toe te passen.

In de tweede plaats dient de accountant ervoor te waken dat ten aanzien van de door hem opgestelde gegevens geen misverstand kan ontstaan wat betreft de nauwkeurigheid en de betekenis der cijfers.

Tenslotte dienen de bestaande methoden voortdurend te worden verbeterd en moet naar meer doeltreffende nieuwe technieken worden gezocht, collectief, maar met medewerking van zoveel mogelijk accountants.

A II - 1

E 635.451：E741.23

The Accountants' Journal, (New Zealand), Juli 1958

\section{LEER VAN DE INRICHTING}

\section{Accounting by Electronic Methods: An Introductory Outline}

Het Engelse Instituut van Accountants publiceert in dit artikel een aantal gegevens en opmerkingen over de aard en de mogelijkheden van elektronische apparatuur en de problemen met welke de gebruiker hiervan geconfronteerd wordt.

A III -3

Accountancy, juli 1958

E 738.4

\section{LEER VAN DE CONTROLE}

\section{Rotation of auditors}

L o y a $11 \mathrm{M}$ c L a r e $\mathrm{n}, \mathrm{N}$. - Hier wordt de vraag besproken, of het voor cliënten gewenst is van tijd tot tijd van accountant te veranderen, en in hoeverre dergelijke veranderingen in het belang van het algemene publiek zijn.

Hoewel de wisseling van accountants ongetwijfeld een nieuwe kijk op de gegevens en problemen met zich kan brengen, wordt dit voordeel in het algemeen te duur betaald. De schrijver komt dan ook tot de conclusie dat rouleren van accountants niet in het algemeen belang is en ook voor de cliënt meer nadelen dan voordelen medebrengt. 


\section{Trends in Audit Practice}

$\mathrm{Sm}$ ith, St. Elmo V. - De veranderingen die zich gedurende de laatste 30 à 40 jaar hebben voorgedaan in het karakter van de accountantscontrole en in de verantwoordelijkheid van de accountant worden vrij uitvoerig behandeld, waarbij uitgegaan wordt van de Canadese verhoudingen.

De nadruk is bij de controle meer komen te liggen op het al dan niet juist weergegeven zijn van de financiële positie en de resultaten van de onderneming in de jaarstukken. Het controleren op fouten in de boekhouding en fraudes als zodanig is meer op de achtergrond gekomen; wel is het de taak van de moderne accountant, erop toe te zien dat door een juist georganiseerde interne controle eventuele fouten en fraudes aan het licht komen.

Nieuwe ontwikkelingen zijn gedurende de laatste 10 of 15 jaar in Canada opgetreden ten aanzien van het controleren van de debiteurensaldi door directe correspondentie van de accountant met de debiteuren en met betrekking tot het - soms steekproefsgewijs waarnemen van de inventarisering of het zelf opnemen van voorraden door de accountant of zijn staf. De schrijver verwacht dat deze onderdelen meer en meer algemeen deel van de controle zullen gaan uitmaken.

Een andere recente ontwikkeling is het spreiden van de controle-arbeid over een groter gedeelte van het jaar. Dit is een gunstig verschijnsel; het kan ertoe bijdragen dat de controle grondiger en met meer zorg geschiedt.

De schrijver richt vervolgens het oog op de toekomstige ontwikkeling. Hij verwacht in bepaalde gevallen een verdere toename van de spreiding van de controle-arbeid over het jaar. In verband daarmee staat dat de interne controle meer en meer een steun voor het accountantsonderzoek gaat vormen waardoor de hoeveelheid door de accountant uit te voeren detailarbeid verder vermindert. Ook meerdere toepassing van steekproeven wordt mogelijk geacht.

Tot slot wordt een beschouwing gewijd aan de ontwikkeling der accountantscontrole bij invoering van elektronische administratie en aan het probleem van de opleiding van mensen voor het accountantsberoep.

A IV -1

E $635.451:$ E 741.23

The Canadian Chartered Accountant, augustus 1958

\section{Standards for the Review of Internal Control}

M a u t z, R. K. - Dit artikel handelt over de vraag, hoe ver de openbare accountant dient te gaan bij zijn onderzoek naar de effectiviteit van de interne controle. Teneinde dit probleem duidelijk te stellen, geeft de schrijver een vijftal gedragslijnen voor het toetsen van de interne controle, weike als "standaarden" zouden kunnen dienen.

A IV -2

E 635.451 : E 641.223.11

The Journal of Accountancy, juli 1958

\section{De steekproef in de accountantscontrole I}

L o u wers, P. C. - De vraag naar de principiële toelaatbaarheid van steekproeven in de accountantscontrole kan niet worden losgemaakt van de vraag of en zo ja in hoeverre de accountant mag of moet steunen op de interne controle. De schrijver geeft dan ook eerst een analyse van de ontwikkeling van de opvattingen in Nederland ten aanzien van de betekenis van de interne controle voor de accountant, en vervolgens een kort overzicht van de opvattingen welke in de Verenigde Staten over deze kwestie worden gehuldigd.

A IV - 2

Maandblad voor Accountancy en Bedrijtshuishoudkunde, juni 1958 E $76:$ E $635.451:$ E 741.23

\section{B. BEDRIJFSHUISHOUDKUNDE}

\section{a. ALGEMENE BEDRIJPSHUISHOUDKUNDE}

\section{WAARNEMINGSMIDDELEN}

\section{Betriebsvergleich}

Een nummer van het tijdschrift „Wirtschaftlichkeit”, dat ter gelegenheid van het 10-jarig bestaan van dit periodiek verscheen, is gewijd aan de vraagstukken welke verband houden met de bedrijfsvergelijking.

Het bevat een zestal artikelen, o.m. over bedrijfsleiding en bedrijfsvergelijking, de methodiek der bedrijfsvergelijking en het verband met de produktiviteitsbevordering en de efficiencybewaking. Ook aan de toepassing van bedrijfsvergelijking in de Oostenrijkse katoenspinnerijen en in de papier- en celstofindustrie zijn beschouwingen gewijd.

Ba III - 1

E. 76

„Wirtschaftlichkeit", ne 1/2 1958

\section{m a b blz. 464}




\section{LEER VAN DE KOSTPRIJS EN DE PRIJSVORMING}

\section{Winst van economisch standpunt en van het standpunt van de accountant}

M e y, J. L. - Het referaat van de Deense hoogleeraar en accountant Palle Hansen op het zevende internationale accountantscongres vertoont een ongewone benadering van het vraagsiuk van de Winstbepaling in de Onderneming. De schrijver van het artikel verwerpt de redenering van Hansen als uitgangspunt voor een berekening van de winst van economisch standpunt. Toch acht hij dit referaat van belang, omdat het een stimulans vormt voor accountants, zich rekenschap te geven van de consequenties van het betrekken van de economische winst in hun rapportering.

In het artikel wordt in dit verband o.m. de vraag behandeld, in hoeverre men de toekomst in zijn waardering betrekt wanneer van de vervangingswaarde wordt uitgegaan; de schrijver meent dat dit inderdaad gebeurt, en gaat na welke houding de accountant hiertegenover in dient te nemen. Hij acht het begrijpelijk dat vele accountants deze moeilijkheid wensen te ontgaan en in hun rapport niet verder willen gaan dan een ,record of history".

Ba IV - 8

De Naamlooze Vennootschap, juli-augustus 1958

E 253

\section{LEER VAN DE FINANCIERING}

\section{Evaluation of Stock Dividends}

B a r k e r, C. A. - De betekenis van stockdividenden is een onderwerp, waarover veel meningsverschillen bestaan en dat de laatste jaren op de voorgrond staat omdat er zoveel stockdividenden worden uitgekeerd. De schrijver deelt de stockdividenden in in drie soorten. De eerste soort gaat gepaard met een stijging in het gewone dividend, de tweede met gelijkblijvend of dalend dividend, terwijl bij het derde type iedere betaling van dividend in contanten achterwege blijft. Voor vele gevallen van elk van deze typen is nagegaan welk effect het declareren van het stockdividend heeft gehad op de beurskoers van het aandeel. Het onderzoek omvat alle stockdividenden van $5 \%$ of meer op gewone aandelen welke op de New York Exchange genoteerd waren in de jaren 1951 tot en met 1954.

Deze gegevens tonen dat stockdividenden géén blijvende gunstige invloed op de beurskoersen hebben. Dit geldt zowel voor kleine als voor grotere stockdividenden. Ook zijn ze duur voor de onderneming en lastig voor de belegger.

Indien men stockdividenden wil declareren om de beurskoers te drukken, kan men het best éen groter stockdividend kiezen en niet meerdere kleine. Veelal is het splitsen van de bestaande aandelen nog een betere oplossing. Bepalend voor de koersen is uiteindelijk de capaciteit van de onderneming om gewone dividenden te declareren in de toekomst; met stockdividenden verandert men daaraan niets wezenlijks.

$\mathrm{Ba} \mathrm{V}-3 \mathrm{a}$

Harvard Business Review, juli-augustus 1958

E 346.1

\section{LEER VAN DE ORGANISATIE}

\section{Why the Supermarket Pays}

In dit artikel wordt op grond van de Engelse ervaringen van de laatste drie jaren een analyse gegeven van de voor- en nadelen van de supermarket. De belangrijkste bron van besparingen wordt gezien in de verlaging van arbeidskosten; deze is niet zozeer een gevolg van zelfbediening alléén, doch wordt pas belangrijk wanneer de onderneming tevens zeer groot wordt. Ook de voordelen welke kunnen liggen in de verkoop van vlees, groenten en fruit, huishoudelijke artikelen, boeken en papierwaren e.d. worden pas voor grote ondernemingen met een aantal vestigingen zo gunstig dat de daaraan verbonden risico's en nadelen erdoor in de schaduw worden gesteld.

Een ernstig probleem is dat van de winkeldiefstallen door consumenten; bij de gewone winkel doet zich dit nauwelijks voor. Ook de toename van de vereiste investeringen op lange termijn is een nadeel, o.m. omdat grote omzetten een absolute voorwaarde zijn voor het renderen van supermarkets en het tevoren schatten van de in een bepaalde omgeving te bereiken omzetten nog zeer moeilijk is.

Men weet nog niet bij welke bedrijfsomvang de besparingen het grootst zijn. Voorlopig is de supermarket nog een verschijnsel van de grote stad. $Z_{i j}$ zal dit misschien nog wel 10 jaar, misschien in Engeland voor een deel altijd, blijven. Het artikel bevat enkele cijfergegevens over de omvang en de investeringen der supermarkets.

De supermarket wint de laatste tijd in Brittannië zienderogen terrein. Dit wordt uitdrukkelijk als een voordeel voor de huisvrouw gezien, omdat het de distributiekosten en daarmede de prijzen verlaagt. 


\section{De Middenstandspolitiek van de staat}

Veldk a m p, D r G. M. J. - In de politieke discussie heeft men twee uiterste stromingen kunnen waarnemen met betrekking tot de doelstelling der middenstandspolitiek, nl. de stroming die de middenstandspolitiek wil bezien vanuit het gezichtspunt van de sociale zekerheid van de ondernemer en die welke deze politiek wil bezien uitsluitend vanuit het gezichtspunt van het ondernemersrisico zonder meer. Daartussen zijn verschillende variaties van mengvormen aanwijsbaar.

De eerstbedoelde stroming is volgens de schrijver moeilijk in overeenstemming te brengen met een op expansie gericht economisch beleid. Het gaat hierbij om beperking van de concurrentie met name door de toepassing van een numerus clausus, om een systeem van prijsgaranties, en om een stelsel van sociale voorzieningen van staatswege voor ogenblikken waarin het ondernemersinkomen van de middenstander ophoudt te vloeien. Deze drie instrumenten voor een op sociale zekerheid van de middenstand gericht middenstandsbeleid worden in hun consequenties besproken. De schrijver ziet ernstige bezwaren, vooral tegen de beide eerstgenoemde en tegen een bevordering van sociale zekerheid langs de derde weg indien deze door de overheid zou worden gehanteerd.

Ook met de middenstandspolitiek waarbij uitsluitend van het ondernemersrisico wordt uitgegaan, is de schrijver het op belangrijke punten oneens. Met name waarschuwt hij tegen het hanteren van een vestigingsbeperking als conjunctuurpolitiek instrument.

Vervolgens zet de schrijver uiteen op welke grondslagen volgens hem een evenwichtige en gezonde middenstandspolitiek moet berusten, en behandelt in dit kader o.m. de onderwijspolitiek, de kredietpolitiek en diverse andere onderdelen van het middenstandsbeleid.

Ba VI - 9

E 626

De Economist, juli/augustus 1958

\section{Structuurwijziging bij de verbruikscoöperaties}

$\mathrm{B}$ a a rt, F. - Tijdens het congres van de verbruikscoöperaties dat onlangs is gehouden is besloten dat men in beginsel naar een snelle concentratie in grote gewestelijke verbruikscoöperaties zal streven, zodanig dat het aantal binnen een beperkt aantal jaren tot een tiende deel van het huidige aantal zal worden teruggebracht.

De redenen hiervoor liggen in de wijziging der omstandigheden, met name wat betreft het transport en de publiciteit, waaraan de formele organisatie der verbruikscoöperaties zich tot dusver niet heeft aangepast. In dit artikel wordt o.m. ingegaan op de problemen van de bedrijfsuitoefening met betrekking tot het kruideniers- en het bakkersbedrijf. Deze problemen liggen deels op technisch, deels op commercieel en op financieel terrein. Vervolgens wordt in het kort de inhoud der reorganisatieplannen geschetst, waarbij ook de gedachte funtcieverdeling tussen de \pm 25 gewestelijke coöperaties en de Centrale ter sprake komt. De schrijver meent dat door de geschetste structuur een aantal der aangeroerde problemen nader tot een oplossing kan worden gebracht en verwacht een belangrijke winst van de leiding der beweging aan kracht en slagvaardigheid.

Ba VI - 10

E 633.233

Economisch-Statistische Berichten, 16 juli 1958

\section{The impact of consumer premiums on marketing efficiency}

B e e m, E. R. - Het spaarzegel- en cadeaustelsel wordt dikwijls aangevallen als zijnde parasitair en schadelijk voor de „,bona fide handel”. De schrijver gaat in op de vraag welke invloed deze systemen in werkelijkheid hebben op de efficiency van de distributie der goederen. Hij onderscheidt daarbij twee gevallen: het "cadeau" - of het tegen gereduceerde prijs verkrijgbare goed - dat reeds bij éen aankoop van het verkochte artikel beschikbaar wordt gesteld, en het "cadeau" waarvoor, in welke vorm dan ook, moet worden "gespaard". De voordelen - ook in maatschappelijke zin - liggen o.m. in het feit dat voor de afzet van het „cadeau" geen afzonderlijke kosten nodig zijn: de verpakking heeft geen verkopende functie, er is geen reclame nodig, het behoeft niet in voorraad gehouden te worden, er wordt geen krediet op verleend, enz.. Ook zijn de bestelhoeveelheden veel groter dan bij afzet via grossier en detaillist in de branche waar het goed thuisbehoort. Dit betekent belangrijke kostenbesparingen. Men kiest dan ook als "cadeaux" gewoonlijk goederen met hoge distributiekosten bij afzet langs de gewone kanalen. Het kan ook zijn dat de "cadeau-markt" een welkom afzetgebied vormt voor een fabrikant met te grote produktiecapaciteit, die dan differentieel calculeert zodat de inkoopprijs van het "cadeau" voor de gever zeer laag komt te liggen.

Bij .,spaar"-systemen zijn er viteraard extra administratiekosten en kosten in verband met de inwisseling der zegels of coupons voor goederen, terwijl ook het introduceren van het systeem bij het publiek kosten medebrengt. Anderzijds zijn er deels dezelfde voordelen als bij het eenmalige "cadeau", deels ook nog andere. Vooral wanneer de spaarzegels 
door een grote organisatie worden uitgegeven en ingewisseld, zijn de kosten van distributie laag. Wel krijgt de consument minder service dan bij aankoop bij een gewone detailhandelaar en heeft hij minder keus, terwijl de aanbiedingen meestal maar gedurende beperkte tijd lopen. Ook moet hij de zegels bewaren, plakken e.d. en heeft hij er alleen wat aan als hij een tijdlang bij dezelfde winkel koopt of hetzelfde merk neemt. Anderzijds zouden vele consumenten de desbetreffende artikelen niet hebben gekocht; het spaarstelsel schept dus additionele afzetmogelijkheden voor de industrie en additionele behoeftenbevrediging voor de consumenten. De prijzen van andere artikelen stijgen er niet door. Ook voor de gewone afzetkanalen is het systeem volgens de schrijver dan ook niet schadelijk.

Als instrument van concurrentie ziet de auteur de spaar- en cadeaustelsels als zeer bruikbaar en ook in sociaal-economische zin nuttig. Waar prijsreducties te klein zouden zijn om effect te sorteren, kan de ondernemer zegels geven. Dit heeft ook het voordeel dat het niet gemakkelijk snel kan worden nagevolgd. De toename van de concurrentie brengt vaak andere bedrijven die geen zegels geven, tot kostenbesparende maatregelen.

$\mathrm{B}$ a VI -15

E 641.252

The Journal of Marketing, juli 1958

\section{Eenhoofdige of meerhoofdige directie?}

L u y k, M r. H. - Het criterium voor de aanwezigheid van een meerhoofdige of een eenhoofdige directie wordt gezocht in de vraag of een college dan wel één persoon de verantwoordelijkheid draagt voor de bedrijfsvoering tegenover aandeelhouders en commissarissen.

De voordelen van eenhoofdige directie liggen o.m. in de mogelijkheid om sneller, soepeler actie te nemen en te reageren, een bepaald beleid duidelijker en consequenter uit te stippelen en te realiseren; daarnaast is b.v. de schaarste van goede directeuren een factor.

Voor tal van ondernemers is de eenhoofdige leiding de enige passende vorm waarin zij hun kwaliteiten kunnen gieten. Dit type ondernemer is vooral waardevol in de beginperiode van de onderneming.

In een meerhoofdige directie bestaat de mogelijkheid van specialisatie; een goede samenwerking binnen de directie is van veel betekenis voor het gehele klimaat in de onderneming, terwijl de meerhoofdige directie ook minder kwetsbaar is dan de eenhoofdige.

$\mathrm{Na}$ deze en andere argumenten vóór en tegen beide vormen te hebben besproken, gaat de schrijver na, in hoeverre aard en omvang van de onderneming van belang zijn voor het probleem van meerhoofdige of eenhoofdige directie. Hij merkt op dat grote veelzijdigheid van de onderneming veelal betekent dat een meerhoofdige directie beter voldoet. Over de invloed van de omvang van het bedrijf kan geen algemene uitspraak worden gedaan: het is meer de phase in de ontwikkelingsgang waarin de onderneming zich bevindt die mede bepalend is.

Tot slot geeft de schrijver een samenvatting van de voorwaarden, waaronder de eenhoofdige resp. de meerhoofdige directie goed kan functionneren.

Ba VI - 16 Doelmatig Bedrijtsbeheer, augustus/september 1958

E 642.411

\section{Verkoopkunde: aangeboren gave of aan te leren bekwaamheid?}

H o o g e we $\mathrm{ff}$, J. J. - Dit artikel geeft in hoofdzaak een samenvatting van hetgeen is gebeurd en besproken op de lustrumbijeenkomst van de Nederlandse Vereniging van Commerciële Directeuren op 10 april j.1.

Het doel van bedoelde vereniging wordt uiteengezet. Vervolgens wordt een overzicht gegeven van haar activiteiten en contacten.

De op de bijeenkomst gehouden voordrachten, waarvan de inhoud in het kort wordt weergegeven, hadden tot onderwerp resp. „De toekomst van de commerciële functie", door de heer Loupart, en "De toekomst van jongeren in het commerciële vak" door Prof. Waterink.

Ba VI - 21

E 641.252

Maandblad voor Bedrijfsadministratie en -Organisatie, augustus 1958

\section{LEER VAN DE ARBEIDSVOORWAARDEN}

\section{Does Automation Raise Skill Requirements?}

B right. J. R. - Het lijkt logisch en vanzelfsprekend dat bij voortschrijdende automatisering steeds hogere eisen aan het personeel worden gesteld. Dit wordt dan ook vrijwel algemeen aangenomen. De loonpolitiek, de recrutering, de onderhandelingen met vakbonden en de opleidingsprogramma's worden op deze aanname gebaseerd. De schrijver onderzoekt in hoeverre deze juist is en komt tot de conclusie dat de feiten in een belangrijk 
aantal gevallen daarmee in strijd zijn. Teneinde het inzicht in deze kwestie te verdiepen, gaat hij na, op welke wijzen de arbeider een bijdrage kan leveren tot de produktie. Voor elk soort bijdrage (bv. lichamelijke inspanning, geestelijke inspanning, handvaardigheid, werkervaring, afbreukrisico, verantwoordelijkheid enz.) wordt vervolgens onderzocht hoe deze verandert naarmate de mechanisering resp. automatisering verder voortschrijdt. In dit ontwikkelingsproces onderscheidt de schrijver 17 stadia. Het resultaat is dat hij voorbij een zeker punt voor vrijwel alle soorten van bijdragen een afname van de eisen constateert, voorzover het reeds bestaande taken betreft. Anderzijds ontstaan nieuwe taken en nieuwe combinaties van taken welke hogere eisen stellen, doch hun aantal is beperkt.

De conclusies berusten op onderzoek van 13 bedrijven met tezamen ongeveer 50.000 personeelleden.

Tot slot wordt ingegaan op de vraag, op welke grondslag het beloningssysteem in een geautomatiseerd bedrijf dient te berusten, en of de arbeiders als groep een aandeel - en zo ja welk - toekomt in de geldelijke voordelen welke de automatisering oplevert. Verschillende mogelijke standpunten in deze worden kritisch beschouwd. De schrijver concludeert dat een algemeen recept niet kan worden gegeven. Een studie van de consequenties van automatisering in elk gegeven geval zal de basis voor de loonpolitiek moeten zijn. Ook met werkclassificatie komt men er meestal niet, omdat "ouderwetse" taken en taken in geautomatiseerde afdelingen moeilijk met hetzelfde werkclassificatiesysteem kunnen worden geclassificeerd.

Ba VII - 1

E 512.121

Harvard Business Review, juli-augustus 1958

\section{Prestatiebeloning bij de gemeenten}

B orgh a e rts, G. H. - De gemeentelijke handenarbeid staat plotseling in de volle belangstelling, doordat op vrij korte termijn voorzieningen dienen te worden getroffen t.a.v. in te voeren prestatiebeloningssystemen. De hierbij optredende praktische moeilijkheden worden nog vergroot door de historisch verklaarbare onvoorbereidheid van het leidinggevende personeel in de meeste gemeenten t.a.v. deze materie en door de vrijwel algehele afwezigheid van arbeidstechnisch personeel. De te nemen risico's zijn groot, en kunnen slechts worden beperkt door van elke voorkomende soort arbeid het karakter te onderzoeken en het daarvoor geschiktste systeem van prestatiebeloning toe te passen. De schrijver rangschikt de voorkomende soorten arbeid naar een drietal gezichtspunten en geeft voorbeelden van de diverse soorten. Vervolgens bespreekt hij de vraag. welke vorm (en) van prestatiebeloning passen bij elk van de onderscheiden arbeidstypen. Vooral het al dan niet voorzienbaar zijn van de duur van de beschouwde arbeid is een belangrijk punt van overweging bij de keuze van het beloningssysteem.

Teneinde een indicatie te verkrijgen inzake de omvang van de diverse soorten arbeid in de praktijk is een globale analyse uitgevoerd bij een willekeurige gemeente. De schrijver geeft de resultaten hiervan, waaruit o.m. blijkt dat er slechts een laag percentage repeterende arbeid is; het stophorloge is bij de gemeentelijke arbeid dus veelal niet op zijn plaats. Dit betekent echter niet dat men op merit-rating aangewezen zou zijn: de schrijver geeft een tussenvorm, die voor de grootste groep van vaklieden aanvaardbaar wordt geacht. Het beschreven stelsel is exacter dan zuivere merit-rating doch minder exact dan gemeten tarief, en voldoet volgens de schrijver in de praktijk bij gemeentediensten zeer goed. Ba VII - 2

E 641.215 .2

Tijdschrift voor Efficientie en Documentatie, augustus 1958

\section{Prestatiebeloning voor indirect personeel}

S e b u s, D rs. G. M. W. - In een Amerikaans bedrijf heeft men premiebeloning voor alle indirecte personeelleden, tot nachtwakers en verpleegsters toe. In het artikel worden de verschillende systemen uiteengezet, welke daarbij worden toegepast en welke onderling sterk uiteenlopen.

B a VII - 3

E 641.215 .2

Tijdschrift voor Efficiēntie en Documentatie, juli 1958 